\title{
A Basic Characterisation Study of Bioplastics via Gelatinization of Corn Starch
}

\author{
Cindy Li Yin Lee, Wan Sieng Yeo* \\ Department of Chemical Engineering, Curtin University, Malaysia, CDT 250, Miri 98009,
}

Sarawak, Malaysia

\begin{abstract}
Plastic waste is the third-largest waste source in the world, so it raises the world's human health and environmental concerns. Replacing conventional petroleum plastic with bioplastic is an alternative way to minimise plastic wastes from human life and bioplastic is more environmentally friendly. Therefore, this research study aims to synthesise bioplastic from corn starch via gelatinization and study its characteristics. Different from other studies, in this study, new formulations of bioplastics with different ratios of corn starch to glycerol samples that are 1:0.5, 1:1, 2:1, and 2:2, namely Sets A, $B, C$, and D, respectively, were studied and compared. From the Fourier Transformation Infrared Spectroscopy analysis, the results show that all produced cornstarch-based bioplastic samples had the four major plastic's functional groups which indicated that they were categorized as polyester. Meanwhile, via thermal property analysis, all bioplastic samples could be thermally decomposed from $34{ }^{\circ} \mathrm{C}$ to $504{ }^{\circ} \mathrm{C}$ where their weight was reduced from $5 \mathrm{mg}$ to $1 \mathrm{mg}$. Among the four bioplastic samples (Sets A to D) with different ratios of corn starch to glycerol, it was found that the ratio of corn starch and glycerol was 1:0.5 (Set A) had more biodegradable characteristics and it had the lowest water holding capacity. From the results, Set A could only hold around $4.27 \%$ of the water that could avoid the interaction of water with the contents that were wrapped. Besides, from the results, Set $A$ could degrade better in soils, and dissolve more in ethanol, acetone, and oils when compared to other samples. Since the bioplastic can degrade naturally by the ethanol produced from bacteria in the soils under anaerobic reactions, thus Set A has the potential application to be used as a fertiliser coating to minimise the fertiliser release rate in regions under heavy rainfall.
\end{abstract}

Keywords: Bioplastic, glycerol, corn starch, gelatinization, fertiliser coating.

\section{Introduction}

In the past 60 years, human beings had generated 8 billion tons of petroleum-based plastic globally, and the production rate of plastic is still increasing [1]. Some popular materials are commonly used to manufacture plastic, including polyethylene, polyvinyl, and polystyrene [2]. Plastic applications include medical applications, food packaging, toys, containers, mobile items, sports items, etc. [3]. However, improper plastic waste management and inappropriate human behaviour lead to the accumulation of an abundance of plastic waste [14]. Most petroleum-based plastics are longestablished plastics that are less sustainable as compared to bio-based plastics [5] and they are difficult

\footnotetext{
* Corresponding author. Tel.: +60 $85630100($ GMT +8) Ext: 2471; fax: +60 85630088

E-mail address: christineyeo@curtin.edu.my
}

Manuscript History: Received 23 May, 2021, Revised 13 July, 2021, Accepted 15 July, 2021, Published 31 October, 2021 Copyright (C) 2021 UNIMAS Publisher. This is an open access article under the CC BY-NC-SA 4.0 license. https://doi.org/10.33736/jaspe.3445.2021

e-ISSN: 2289-7771

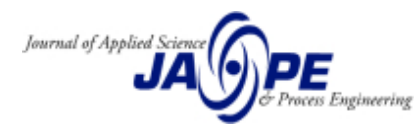


to be recycled [6]. In addition, these petroleum-based plastics are usually broken down into microplastics that have the potential to affect marine ecosystems and human health [7].

Bioplastics are classified into biodegradable and bio-based plastics. Bio-based plastics focus on the raw material used while biodegradable plastics focus on the ability of the final products to decompose [8]. Biodegradable plastics are compostable, but bio-based plastics can be nonbiodegradable [9]. Apart from that, during the biodegradation process of plastics, greenhouse gases such as carbon dioxide are released into the surrounding [10]. Biodegradable plastics can be made up of fossil, blends of renewable or renewable resources. However, the final formed chemical structure of bioplastics can affect their biodegradability. Therefore, the raw materials of bioplastics that affect the final chemical structure of bioplastics including their functional group need to be taken into consideration [11].

On the other hand, biodegradable bioplastics can be photodegradable, and biodegradable [12]. Photodegradable bioplastics are sensitive to light [10] in which the light-sensitive groups that link the backbone of the polymer bioplastics function as addictives to capture the light for the degradation process [12-13]. Moreover, the polymeric structure of bioplastics is degraded if it is exposed to extensive ultraviolet radiation for long periods and that is also considered photodegradation. Later, this scenario can allow the disintegrated bioplastics to undergo further bacterial degradation [2]. However, the photodegradation of bioplastics can be difficult when the natural sunlight is insufficient to carry out the process. Therefore, the biodegradation of bioplastics is more promising than the photodegradation of bioplastics.

Despite that, the biodegradable plastics that are made from microorganisms can form biopolymer which includes polyhydroxyalkanoate, aliphatic polyesters, polylactides, and polysaccharides [14]. Also, there is semi-biodegradable plastic that is a kind of starch linking plastic that connects the short fragments of polyethylene or polyethylene [15]. However, this type of bioplastic cannot be decomposed fully due to the fragment of polyethylene or polyethylene that will prevent the bacteria from attacking the starch and some environmental factors [2]. Thus, it can be said that different types of bioplastics have dissimilar chemical, physical, mechanical, and biological properties. Moreover, these properties may change over time which leads to the different levels of tissue compatibility from their raw materials and they become hard to degrade.

Therefore, biodegradable plastics should not emit a prolonged erythrogenic and toxic reaction to human's health while having an accepted usable period. Moreover, the regeneration process time of bioplastics should be the same as the degradation process. Also, during the degradation process of bioplastics, it should not release any toxic or harmful substances that are unable to be metabolized or cleared by a human's body. Additionally, its permeability and processability should be appropriate for its application [16]. However, the production cost of bioplastics can be high, which cannot be produced on a large scale to replace petroleum-based plastics [17]. Thus, corn starch can be one of the most convincing raw materials due to its low cost and availability [18] According to [19], corn is cultivated and harvested in many areas of Malaysia. The cultivation area for corn in Malaysia is around 11,713 hectares in the year 2018 and the annual production of the corn is about 84,170 tonnes [19]. Also, starch contains a long chain of two glucose units that are joined together, which is also known as polymerised amylopectin and amylose. Moreover, starch-based bioplastic can behave like thermoplastic and have improved heat and mechanical properties [18].

This project aims to produce biodegradable cornstarch-based bioplastic via gelatinization in a simple, more eco-friendly, and environmentally friendly way. Corn starch is used as it is already available in commercial packaging materials at a cheap price and it has a higher amylose content as compared to other starch sources which will provide a more stable decomposition temperature. Different from other studies, in this study, new formulations of bioplastics with different ratios of corn starch to glycerol samples were 1:0.5, 1:1, 2:1, and 2:2, namely Sets A, B, C, and D, respectively, were studied and compared. Several characterization analyses were performed, and they were Fourier transformation infrared spectroscopy (FT-IR) analysis, thermal properties analysis (TGA), and 
biodegradation analyses including water absorption analysis, soil degradation analysis, photodegradation analysis, dissolution in acetone, ethanol, and oil analysis.

\section{Materials and methods}

\subsection{Materials and equipment}

To synthesise corn-starch-based bioplastic, materials that were required were corn starch with $25 \%$ amylose content, distilled water, and vinegar with $5 \%$ to $6 \%$ of Acetic acid. Besides, glycerol with a purity of $98 \%$ was used as a plasticizer in this project. Meanwhile, other general laboratory equipments required were small beakers, a hot plate with a magnetic stirrer, spatula, weighing machine, pipette, and Petri dishes. An FT-IR spectrophotometer was used to identify the functional group of the produced corn starch-based bioplastics with different ratios of corn starch to glycerol samples that were 1:0.5, 1:1, 2:1, and 2:2, namely Sets A, B, C, and D, respectively. Besides, the TGA was used for the thermal properties analysis.

\subsection{Preparation of corn-starch-based bioplastic}

The corn-starch-based bioplastic was synthesised via a following modified method that was originally taken from [20], and [21]. Two grams of corn starch was prepared in a small beaker. $12 \mathrm{~mL}$ of distilled water, $1 \mathrm{~mL}$ of vinegar, and $1 \mathrm{~mL}$ of glycerol were added into the beaker and mixed well with corn starch. Vinegar was diluted with Acetic acid which was used to break down the amylopectin. Also, Acetic acid can change the structure and properties of the polymer. The mixture was then transferred to a hot plate and heated under $150{ }^{\circ} \mathrm{C}$. The mixture was stirred constantly with the stirrer until it boiled. When the mixture turned transparent, the hot plate was turned off. The mixture continued stirring for 2 to 5 minutes. After 2 to 5 minutes, the mixture was placed on the petri dish and moulded as thinly as possible. The mixture was placed and dried at room temperature. Then, the bioplastic was removed from the petri dish carefully when it was completely dry. As mentioned earlier, new formulations with four sets of different ratios of corn starch to glycerol samples that were 1:0.5, 1:1, 2:1, 2:2, were conducted and they were indicated as Sets A, B, C, and D, respectively. All these samples were also then investigated under characterisation methods and biodegradation analyses to determine their properties and characteristics.

\subsection{Characterisation methods}

\subsubsection{Fourier transformation infrared spectroscopy analysis}

This FT-IR spectroscopy analysis was carried out to assess the chemical structure of the produced bioplastic, especially the identification of chemical functional groups in the testing samples. In this study, the FT-IR instrument used to perform FT-IR spectroscopy analysis was the Agilent model (Cary 630 Agilent), Bruker makes, ALPHA II with 350 to 8,000 wavelengths. The FT-IRspectra of the bioplastic samples were surveyed between 4,000 to 5,000 per centimetre in the transmittance mode.

\subsubsection{Thermal properties analysis}

In this study, TGA and differential scanning calorimeter (DSC) were used to analyse the thermal properties. TGA with the model of TGA/DSC1 that was manufactured from Mettler Toledo and has a maximum operating temperature of $1600{ }^{\circ} \mathrm{C}$ was utilised for thermal properties analyses. The purpose of TGA was to measure the change in mass of the bioplastic when the temperature and time vary under a controlled atmosphere. This analyser should be assisted by the Pyris software. The

e-ISSN: 2289-7771

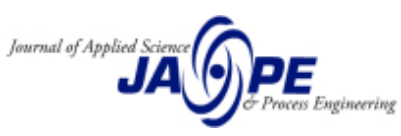


TGA thermographs were recorded under a few conditions, including a temperature range of $30{ }^{\circ} \mathrm{C}$ to $500{ }^{\circ} \mathrm{C}$, a heating rate of $5{ }^{\circ} \mathrm{C}$ per minute, and a nitrogen atmosphere that had a flow rate of $50 \mathrm{~mL}$ per minute.

\subsubsection{Biodegradation analysis}

In this section, biodegradation analyses included four aspects: water absorption, as well as degradation in soil, photodegradation, and dissolution in acetone, ethanol, and oil, were carried out to analyse the properties of the bioplastic. All these analyses could reflect the biodegradability properties of bioplastic and then determine the possible application and function of the produced bioplastic. For each biodegradation analysis, all the samples were cut into $1.5 \mathrm{~cm} \times 1.5 \mathrm{~cm}$. Meanwhile, for each of the biodegradation analyses, the relative change percentage (RC) for the weight of bioplastics was measured using the following equation (1) that was taken from [22]:

$R C=\left|\frac{x_{2}-x_{1}}{x_{1}}\right| \times 100$

where $\mathrm{x}_{1}$ and $\mathrm{x}_{2}$ indicate the initial and final weights of the bioplastic, respectively after the designated biodegradation analysis.

\subsubsection{Water absorption analysis}

In this study, the water absorption test was done on the bioplastic samples according to the American Society for Testing and Materials D570-98 [23]. Some modifications were made in which the immersion method in distilled water at room temperature for 270 minutes. The samples were weighed, and the initial weights were recorded. Next, the samples were placed in the beakers that were filled with water. The samples were taken out of the water every 30 minutes. After the samples were dry, the final weights of the samples were measured. The water absorption test was repeated for 4 hours and all weight data were collected. The RC of the samples indicating the amount of water absorbed by the bioplastics were calculated using (1).

\subsubsection{Soil degradation analysis}

The samples were weighed, and the initial weights were recorded. The samples were buried in the mineral soil taken from Curtin University Malaysia, Miri, Sarawak, Malaysia in the beakers. The samples were taken out from the soil after 1 day. The samples were cleaned, and then their final weights were collected and recorded. The same procedures were repeated for 7 days and all weights were rewritten down. Later, the RC of the samples that showed the soil degradation rates of the bioplastics were determined using (1).

\subsubsection{Photodegradation analysis}

The samples were weighed, and the initial weights were recorded. Next, the samples were placed under sunlight in Miri, Sarawak, Malaysia with the temperature of $26{ }^{\circ} \mathrm{C}$ to $32{ }^{\circ} \mathrm{C}$ [24] for 7 hours per day. During the photodegradation analysis, there was no rainy day. The samples were collected and weighed every day. Any dirt on the surface of the samples was removed, and then the final weights were recorded. The same steps were repeated for 7 days, and the weight data were recorded. Then, the RC of the samples which denoted the photodegradation rates of the bioplastics were obtained using (1).

e-ISSN: 2289-7771

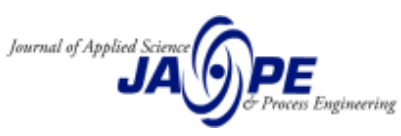




\subsubsection{Dissolution in acetone analysis}

The samples were weighed, and the initial weights were recorded. Then, the samples were placed in the beakers filled with acetone, and the samples were completely immersed in the acetone. The beakers were covered with the preservative parafilm. The samples were taken out of the acetone every 30 minutes. The samples were dried, and then the final weights were recorded. The same procedures were repeated for 4 hours, and the weights data were collected. After that, the RC of the bioplastics which displayed the dissolution rate of bioplastic in acetone were calculated via (1).

\subsubsection{Dissolution in ethanol analysis}

The samples were weighed, and the initial weights were recorded. Then, the samples were placed in the beakers filled with ethanol, and the samples were completely immersed in the ethanol. The beakers were covered with parafilm to avoid the evaporation of ethanol. The samples were taken out from the ethanol every 30 minutes. The samples were then cleaned, and then the final weights were recorded. The same steps were repeated for 4 hours and the weights data were collected. Next, the RC of the samples which illustrated the degradation rates of the bioplastics in ethanol was calculated using (1).

\subsubsection{Dissolution in oil analysis}

The samples were weighed, and the initial weights were recorded. Then, the samples were placed in the beakers filled with Red Eagle cooking oil from Yee Lee Corporation Group. The oil is a refined, bleached, and deodorised palm olein with high-quality groundnut oil and sesame oil for better aroma and flavour. Then, the samples were completely immersed in the oil. The beakers were covered with the preservative parafilm, and then the samples were taken out from the oil every 30 minutes. After that, the remaining oil on the surface area of the samples was removed and the final weights were recorded. The same steps were repeated for 4 hours and all weight data were collected. Later, the $\mathrm{RC}$ of the bioplastics that indicated the degradation rates of the bioplastics in oil were determined using (1).

\section{Results and Discussion}

\subsection{Fourier transformation infrared spectroscopy (FT-IR) analysis}

Due to the same raw materials used to produce the sets of bioplastics, thus, all the bioplastic samples showed the same FT-IR spectra. According to [25], starch including corn starch is semicrystalline material that is the granules consist of rotating crystalline and amorphous regions. These regions are mainly formed by the amylose and amylopectin polymers in which the outer branches are hydrogen-bonded to each other to make crystallites that unravel during gelatinization. Hence, the carboxyl hydroxyl functional groups of amylopectin as well as a glycosidic bond should have $\mathrm{O}-\mathrm{H}, \mathrm{C}-\mathrm{O}$ and $\mathrm{C}=\mathrm{O}$ bonds [26]. Figure 1 shows the FT-IR spectra of the produced bioplastic samples. As shown in Figure 1, the broad bands at 3,279.94 $\mathrm{cm}^{-1}, 2,932.76 \mathrm{~cm}^{-1}, 1,647.48 \mathrm{~cm}^{-1}$, and $1,028.06 \mathrm{~cm}^{-1}$, are the $\mathrm{O}-\mathrm{H}$ stretching, $\mathrm{C}-\mathrm{H}$ stretching, $\mathrm{C}=\mathrm{O}$ stretching and $\mathrm{C}-\mathrm{O}$ bonding, respectively [27]. For other native starch-based bioplastics including potato and yam starch-based bioplastics [28], the wavenumbers of FT-IR results for the $\mathrm{C}=\mathrm{O}$ functional group are 1,644.99 and 1,646.77 $\mathrm{cm}^{-1}$, respectively. These values are close to the wavenumber for the $\mathrm{C}=\mathrm{O}$ functional group of the produced bioplastics which is $1,647.48 \mathrm{~cm}^{-1}$ as shown in Figure 1.

e-ISSN: 2289-7771

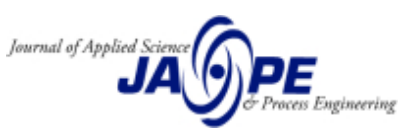




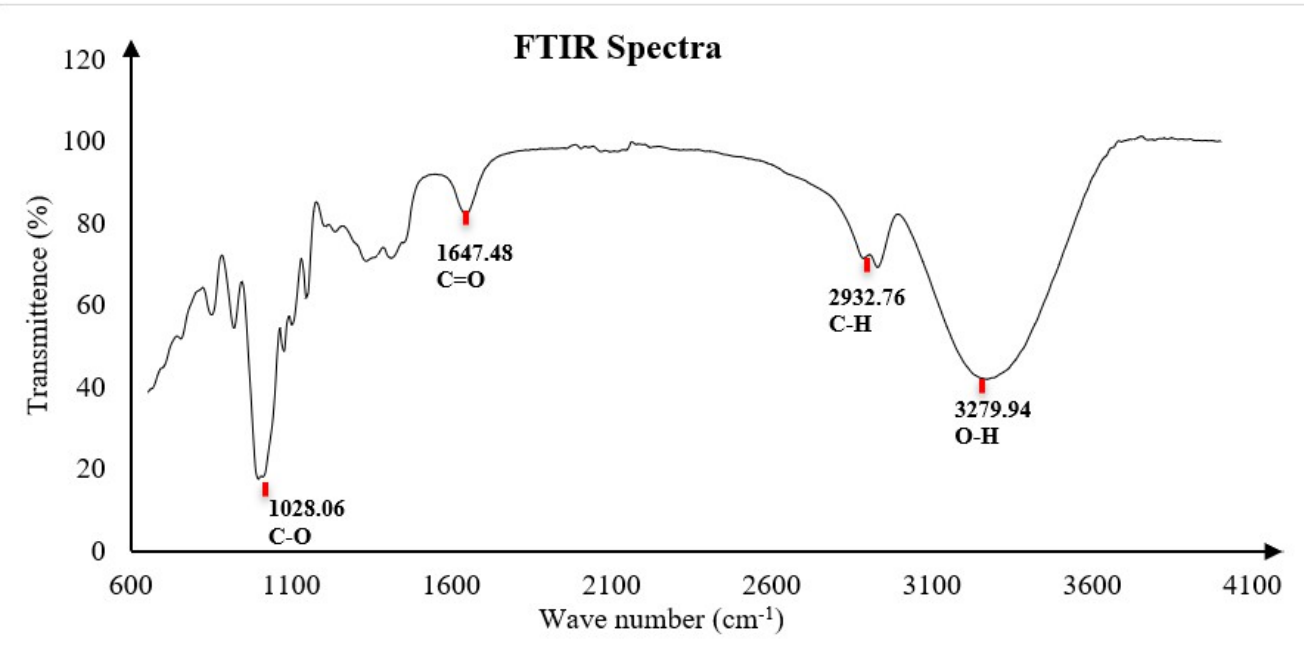

Figure 1. FT-IR spectra for corn starch bioplastic

Starch spectra revealed the $\mathrm{C}=\mathrm{O}$ groups from phosphate groups and even native, unmodified starches exhibited bands in the 1,645 to $1,648 \mathrm{~cm}^{-1}$ range. Moreover, carboxylic groups could occur due to Acetic acid presence from vinegar. Besides, cornstarch-based thermoplastic done by [28] also demonstrated similar wavenumbers as the produced bioplastics in this study. They were $3,277 \mathrm{~cm}^{-1}$ for $\mathrm{O}-\mathrm{H}$ stretching, $2,914 \mathrm{~cm}^{-1}$ for $\mathrm{C}-\mathrm{H}$ stretching, $1,648 \mathrm{~cm}^{-1}$ for $\mathrm{C}=\mathrm{O}$ stretching, and $1,148 \mathrm{~cm}^{-1}$ for $\mathrm{C}-\mathrm{O}$ bonding. In the presence of these four major functional groups, the produced corn starch-based bioplastics are categorized as polyester [29]. These results have illustrated that the produced samples are polymers that consist of functional groups. Moreover, the results of the FT-IR for the produced bioplastics in this study are also in line with results for starch-based bioplastics from other researchers mentioned in [30].

\subsection{Thermal properties analysis}

All the samples had undergone thermal properties analysis using TGA, and they have shown a similar trend in the TGA curve, as shown in Figure 2. Based on Figure 2, bioplastic samples showed two categories of decomposition. The first stage was from $34{ }^{\circ} \mathrm{C}$ to $272{ }^{\circ} \mathrm{C}$, where the water content in the bioplastic gradually evaporated as the boiling point of water is $100^{\circ} \mathrm{C}$. Besides, the small amount of vinegar also evaporated in this stage since vinegar, which has a boiling point of $118.1{ }^{\circ} \mathrm{C}$ is more volatile than glycerol. As a result, the bioplastic lost approximately $40 \%$ of its weight, from $\sim 5 \mathrm{mg}$ to $\sim 3 \mathrm{mg}$. 


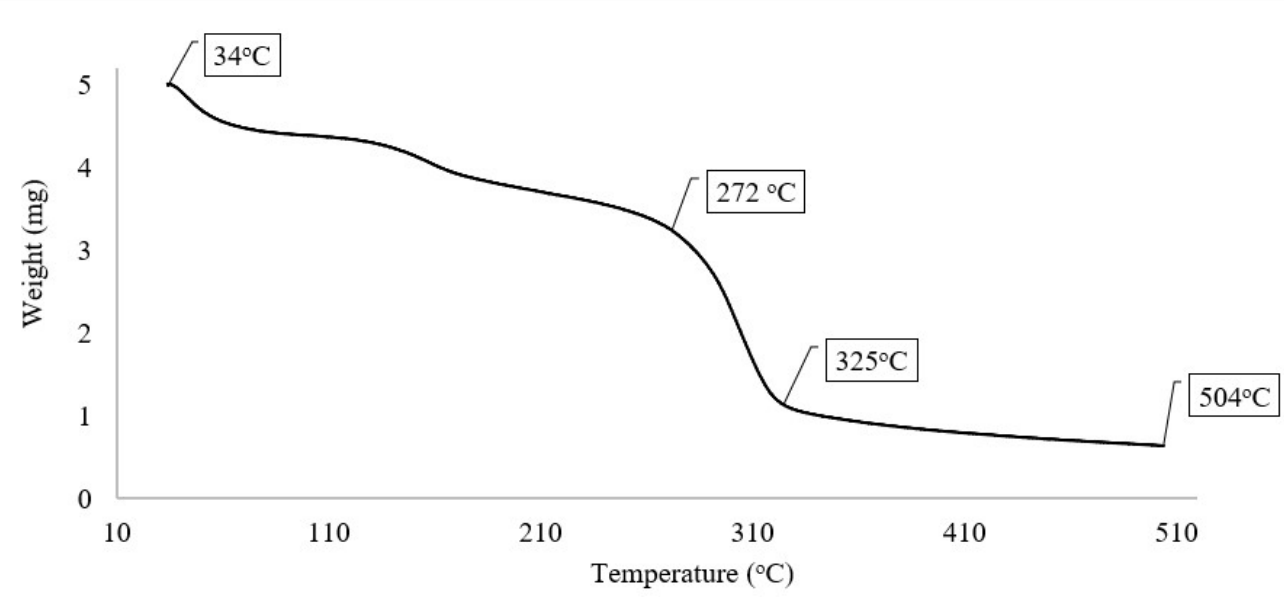

Figure 2. TGA curve for bioplastic

The second stage occurred between $272{ }^{\circ} \mathrm{C}$ and $504{ }^{\circ} \mathrm{C}$, and a significant drop of bioplastic's weight, from $3 \mathrm{mg}$ to $1 \mathrm{mg}$ was noticed. This result indicated the evaporation of glycerol that has a boiling point of $290{ }^{\circ} \mathrm{C}$. Eventually, the bioplastic was slowly shrunken and completely decomposed at $504{ }^{\circ} \mathrm{C}$. Moreover, [27] also conducted a TGA analysis for starch-based bioplastic and composite bioplastic. The results obtained by Amin et al. showed that $50 \%$ of the weight loss of starch-based bioplastic and composite bioplastics were at $291{ }^{\circ} \mathrm{C}$ and $303{ }^{\circ} \mathrm{C}$ [27]. The concentration of amylose in starch will affect the decomposition temperature. The relationship between decomposition temperature and amylose content is inversely proportional [31] Hence, the higher amylose content in starch will provide a more stable decomposition temperature. According to researchers such as [31] and [32], corn starch has a higher content of amylose compared to cassava, sweet potato, yam, potato, and other starches. Therefore, corn starch was chosen for this study due to its stable thermal properties.

\subsection{Water absorption analysis}

The water absorption of bioplastics was tested, and the results obtained were tabulated in Table 1. From Table 1, it can be seen that Set A had the lowest average water absorption of $4.27 \%$ while Set $\mathrm{D}$ had the highest average of $22.8 \%$ water absorption. Figure 3 shows the weights of all the bioplastic samples in water versus time. In Figure 3, it was found that all sets had low water absorption since their weights were almost constant, and Set A had the lowest water absorption. However, Sets C and B had a slightly increased water absorption rate at 210 and 240 minutes, respectively. It can be said that Sets B and D which had a high content of glycerol absorbed more water than Sets A and C. These results are due to glycerol that has a characteristic of hygroscopic which can increase the moisture content of bioplastic [33]. Therefore, the water absorption ability is correlated to glycerol concentration. Set D, which contained more glycerol as compared to Set A, showed better water absorption ability. 


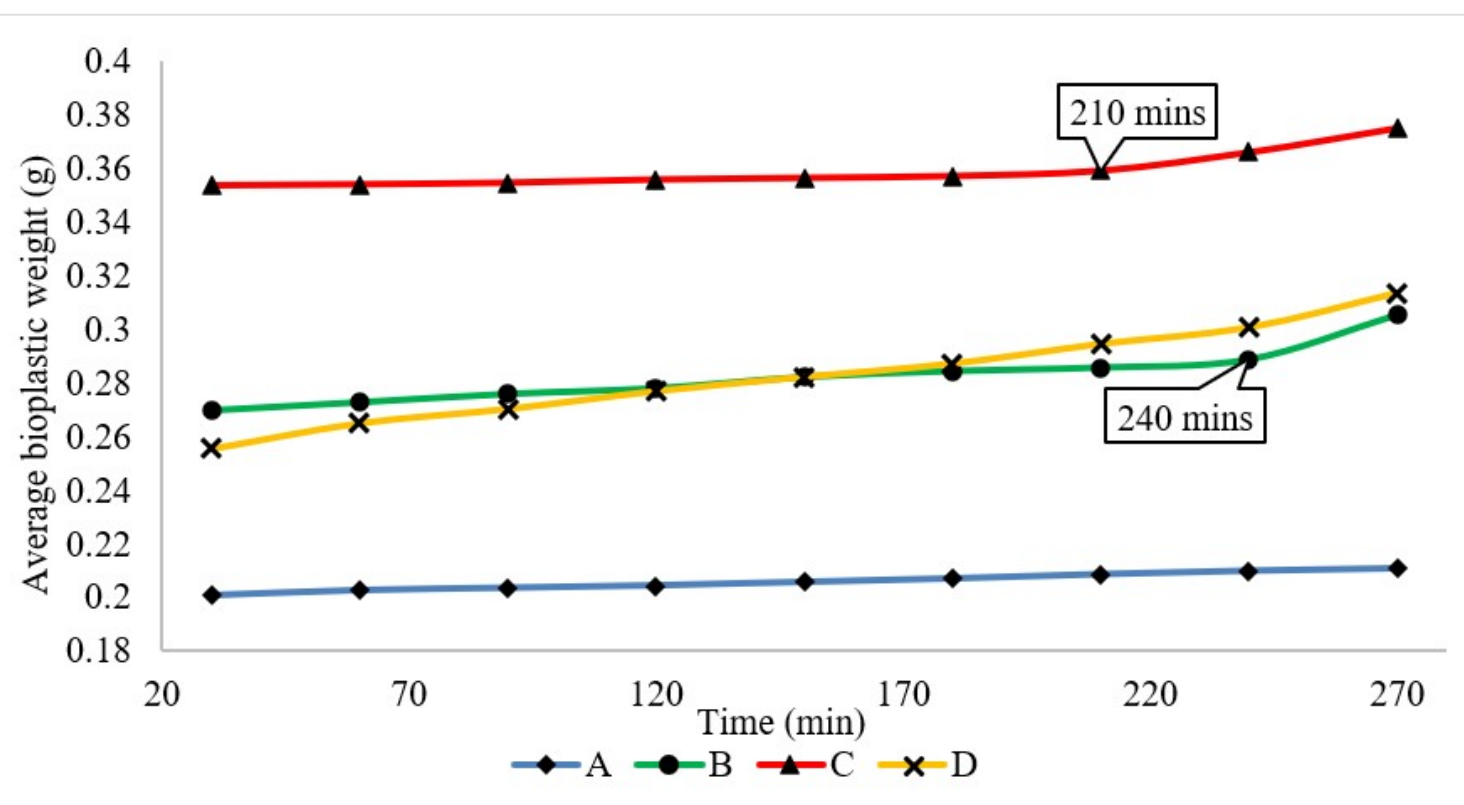

Figure 3. Graph of average bioplastic weight in the water versus time for Sets A, B, C and D

Table 1. Calculation of average and standard deviations water absorption for Sets A, B, C and D

\begin{tabular}{ccc}
\hline Sets & Average CR (\%) & Standard deviations \\
\hline Set A & 4.27 & 2.57 \\
Set B & 11.16 & 4.03 \\
Set C & 6.79 & 1.23 \\
Set D & 22.80 & 6.06 \\
\hline
\end{tabular}

\subsection{Soil degradation analysis}

The produced bioplastics are expected to degrade in soil due to their main raw materials, glycerol, and corn starch. Glycerol is a kind of plasticizer that is sustainable and biodegradable [34]. Meanwhile, a study had proved that corn starch could be biodegraded in soil with the presence of microorganisms in the natural environment [35]. In this study, soil degradation analysis for bioplastic was done for all the samples by burying them in the soil, and the results are summarised in Table 2 . Table 2 shows that the percentages of average soil degradation for four sets from $12.9 \%$ to $9.25 \%$. These results indicated that all the sets were degradable in the soils since there was a reduction of weights. The bioplastics were degraded by microbes in the soil due to their natural materials. These results indicated that the cornstarch-based plastic blended with glycerol could degrade in the soil, and they had environmentally friendly characteristics.

However, Figure 4 that displays the average weights of bioplastic versus time shows that the biodegradable rates of the bioplastic samples were low. In Figure 4, Sets B and D had a similar and better biodegradable rate than Sets A and C. According to [36], the cassava starch plastic blending with the least amount of glycerol requires a longer time, which is 9 days to degrade in soil completely. Thus, these results could be due to the lower content of glycerol in Sets A and C. The higher

e-ISSN: 2289-7771

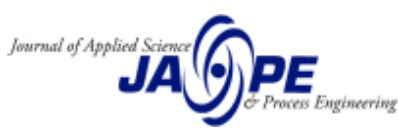


concentration of glycerol that is hydrophilic will attract more water which helps to increase the microbial growth and rapid the degradation process [36].

Table 2. Calculation of average and deviations soil degradation for Sets A, B, C and D

\begin{tabular}{ccc}
\hline Sets & Average CR (\%) & Standard deviations \\
\hline Set A & 12.9470 & 0.37 \\
Set B & 10.1516 & 0.55 \\
Set C & 9.2513 & 0.38 \\
Set D & 9.4518 & 0.13 \\
\hline
\end{tabular}

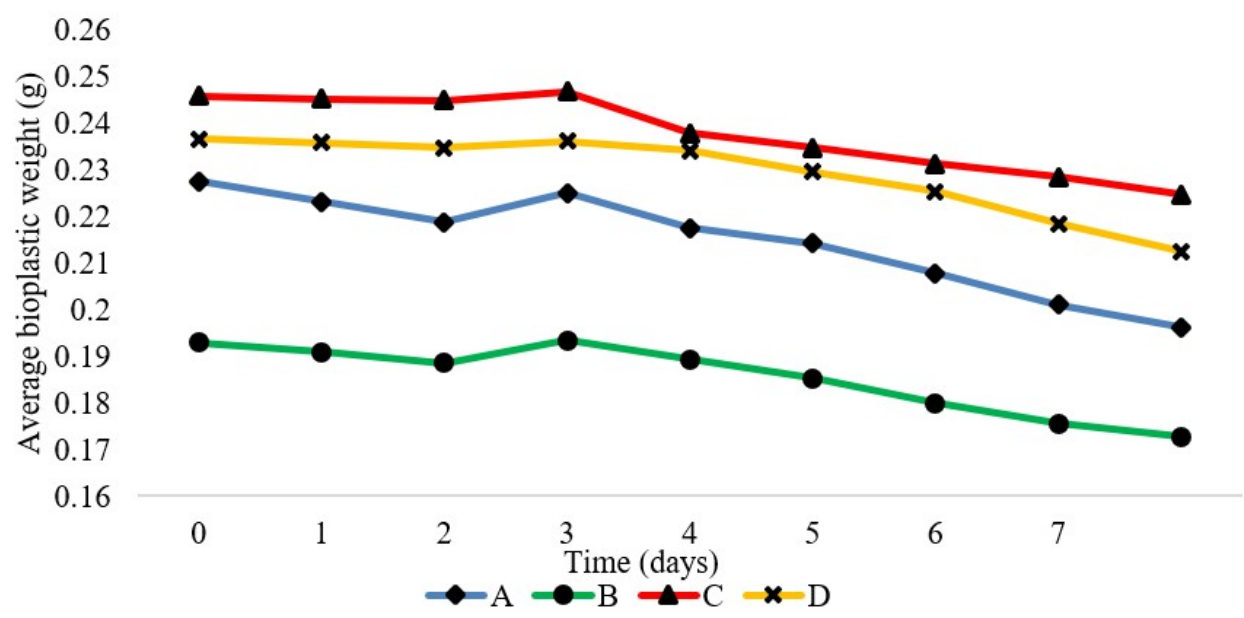

Figure 4. Graph of average bioplastic weight in the soils versus time for Sets A, B, C and D

\subsection{Photodegradation analysis}

Photodegradation is a chemical reaction when the ultraviolet light provided by the sunlight is absorbed by the bioplastic and breakdown down the polymer chain. The obtained results for photodegradation is tabulated in Table 3. All the samples showed a reduction in the average weight of bioplastic. Sets A and C showed almost similar photodegradation percentages, which was around 6.5 $\%$. Meanwhile, Sets B and D showed a low reduction percentage in weight. The higher photodegradation rate was Set A, which was around $0.9 \%$ per day. Set D had the lowest photodegradation rate, which was only $0.5 \%$ per day. In other words, bioplastic will require 105 to 200 days to degrade via sunlight fully. The weather was a huge influence factor in this analysis. Throughout these 7 days, not every day was a sunny day. Instead, some days were cloudy, and it showed a low reduction in weight. For instance, based on Figure 5, day 7 showed the least reduction of weight for all the samples. According to [37], the presence of water will accelerate the degradation of the bioplastic. This is because water will wash off the degraded surface and provide a new surface of bioplastic to carry out photodegradation further [37]. Thus, rainy days will increase the photodegradation rate. 
Table 3. Calculation of average and standard deviations photodegradation for Sets A, B, C and D

\begin{tabular}{ccc}
\hline Sets & Average CR (\%) & Standard deviations \\
\hline Set A & 6.6737 & 1.89 \\
\hline Set B & 4.3433 & 1.75 \\
\hline Set C & 6.5226 & 0.43 \\
\hline Set D & 3.5735 & 0.15 \\
\hline
\end{tabular}

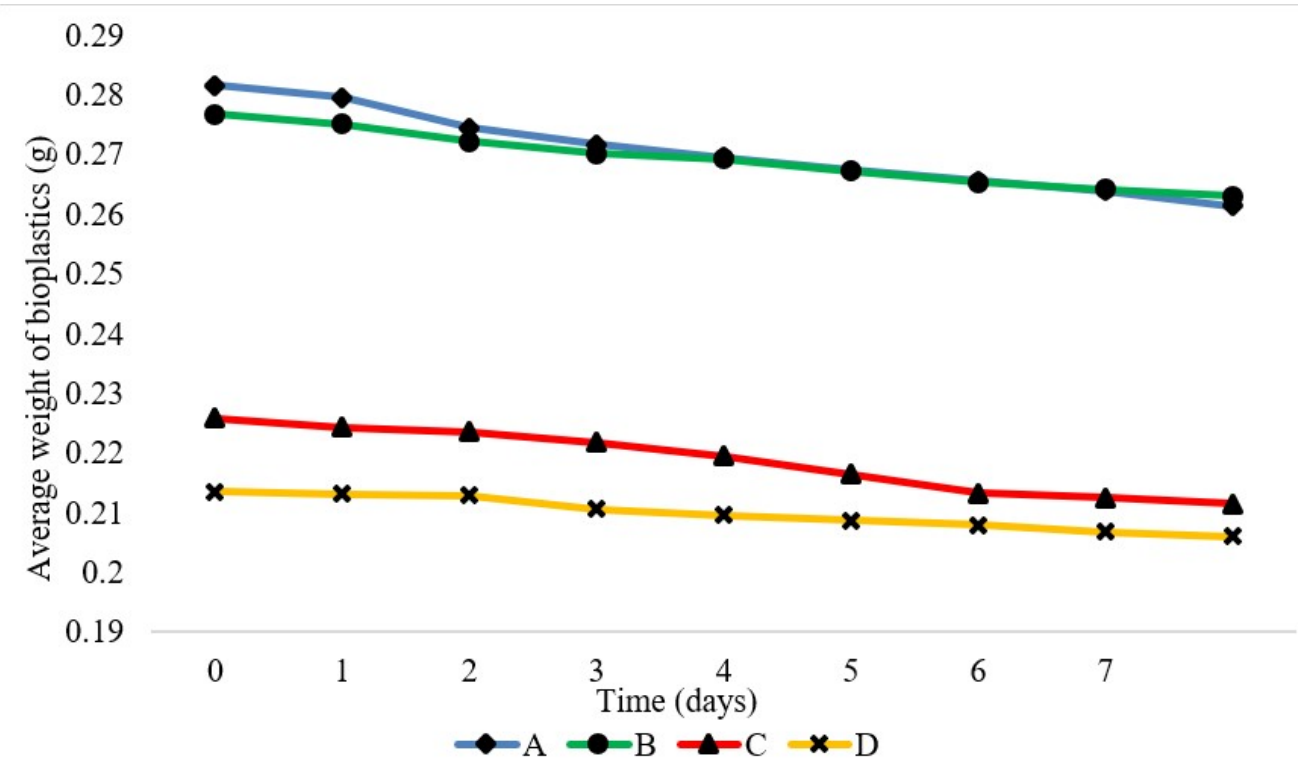

Figure 5. Graph of average bioplastic weight after photo degradation versus time for Sets A, B, C and

$\mathrm{D}$

\subsection{Dissolution in acetone analysis}

Bioplastic samples were immersed in acetone to observe the reaction between acetone which consists of the organic compound, carbonyl group with the bioplastics. All the results obtained were tabulated in Table 4. In Table 4, it is shown that there was little weight change in bioplastic in every set of samples. The average dissolve rate in acetone for all four sets of samples was in the range of 0.6 $\%$ to $1 \%$. These per cent values were relatively small, which can be ignored. However, even though the weight loss of bioplastic was not obvious in this analysis, the properties of bioplastic changed.

During the experiment, the bioplastic became a bit more brittle. Different conditions such as temperature, acetone concentration, external disturbance, etc. will affect the reaction of acetone with glycerol in the bioplastic and acetone can change the character of bioplastic [38]. Acetone is commonly used for sterilisation in ophthalmic surgery or any medical equipment. Hence, these results showed that the produced bioplastics are not recommended to be used in medical industries which use 
acetone as a sterilization reagent too as it will dissolve when contact or immersed in an acetone solution. Besides, they are hard to be recycled using acetone as a solvent because their weight reduction in acetone is too small. It may require a longer time or a higher concentration of acetone to completely dissolve the bioplastic, which is not eco-friendly and economical.

Table 4. Calculation of average and standard deviations dissolve rate in acetone for Sets A, B, C and D

\begin{tabular}{ccc}
\hline Sets & Average CR (\%) & Standard deviations \\
\hline Set A & 1.0566 & 0.15 \\
\hline Set B & 0.7806 & 0.13 \\
\hline Set C & 0.6461 & 0.14 \\
\hline Set D & 0.6056 & 0.08 \\
\hline
\end{tabular}

\subsection{Dissolution in ethanol analysis}

Apart from that, bioplastic was immersed in ethanol as well to investigate the relationship between bioplastic and ethanol, which is organic compound alcohol with a functional group of the hydroxyl group. Table 5 shows the initial and final weights of all the samples precipitate in ethanol. Figure 6 shows the average bioplastic weight loss when reacting with ethanol in the duration of 20 to 270 minutes. As illustrated in Table 5 and Figure 6, Set A showed the highest precipitation rate in ethanol among the sets since it could reduce around $2.5 \mathrm{wt} \%$ in an hour. Besides, Sets $\mathrm{C}$ and $\mathrm{D}$ showed low precipitation rates which were $4.8 \%$ and $4 \%$, respectively. Compared to acetone, bioplastic precipitated much more in the presence of ethanol. Thus, it means that it is easier for bioplastics to be recycled using ethanol than acetone. For its application, these bioplastics are recommended to be used as fertilizer coating since they can be degraded by ethanol from bacteria in the soils that undergo anaerobic reactions.

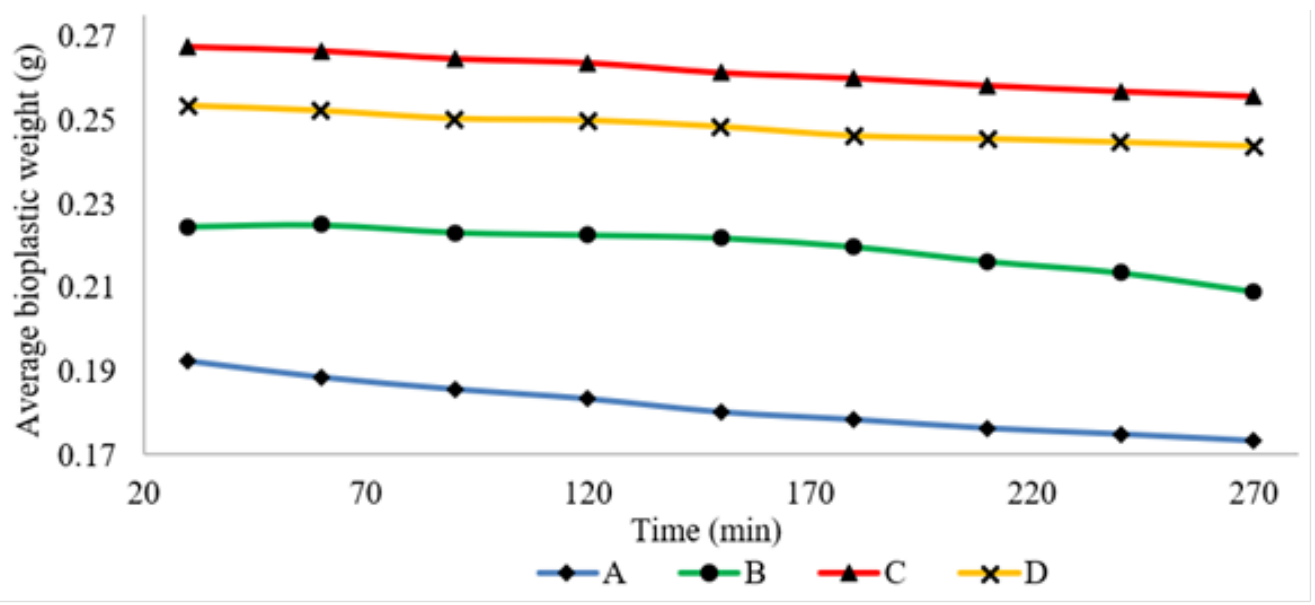

Figure 6. Graph of average bioplastic weight in ethanol versus time for Sets A, B, C and D

e-ISSN: 2289-7771 
Table 5. Calculation of average and standard deviations precipitation rate in ethanol for Sets A, B, C and D

\begin{tabular}{ccc}
\hline Sets & Average CR (\%) & Standard deviations \\
\hline Set A & 10.0831 & 1.90 \\
\hline Set B & 6.6749 & 0.47 \\
\hline Set C & 4.8011 & 1.10 \\
\hline Set D & 4.0247 & 0.63 \\
\hline
\end{tabular}

\subsection{Dissolution in cooking oil analysis}

The results of the dissolution test of bioplastic in cooking oil are tabulated in Table 6 . Based on Table 6 , all the samples showed a very low dissolution rate in cooking oil, which was around $0.2 \%$ to $0.3 \%$ except set D. Set D experienced the least dissolution in cooking oil. Oil-soluble bioplastic is not suggested to be used in the food and beverage packaging industries for oily food such as oil bottles or fried food packaging. The reduction of bioplastic weight in cooking oil is suspected to be due to the release of plastic particles, which are harmful to human health. Apart from that, oil is not suitable to be the medium for dissolving bioplastic for recycling purposes.

Table 6. Calculation of average and standard deviations dissolve rate in oil for Sets A, B, C and D

\begin{tabular}{ccc}
\hline Sets & Average CR (\%) & Standard deviations \\
\hline Set A & 0.3682 & 0.25 \\
\hline Set B & 0.2164 & 0.12 \\
\hline Set C & 0.2964 & 0.16 \\
\hline Set D & 0.0918 & 0.05 \\
\hline
\end{tabular}

\section{Conclusion and future research directions}

In this study, bioplastics were produced from corn starch via gelatinization using different ratios of corn starch to glycerol, and its application is recommended based on its characteristics. It can be concluded that cornstarch-based plastic with a ratio of corn starch to glycerol (1:0.5), which is Set A acts more like plastic as compared to other sets since Set A absorbs less water. Besides, this characteristic makes Set A suitable to be fertilizer coating since it can prevent the fertiliser from contact with water from rain and in the soil before cracking. After it has interacted with the ethanol generated from the soil's bacteria under anaerobic reaction, fertiliser can be released for fertilisation purposes.

On the other hand, it also has a high tolerance temperature, biodegradable in soil, photodegradable, and able to dissolve in ethanol but it does not dissolve in the cooking oils. Thus, if the bioplastic is required to be recycled in the future, it can be dissolved in ethanol and further process to produce other products. Further study is required to investigate how many times it can be recycled. Moreover, further research can be carried out to study the mechanical strength of the bioplastic to improvise the bioplastic by increasing the tensile strength and elongation break for more applications in a different area in future. In addition, more time can be used to study soil degradation. Lastly, 
different types of plasticizers can be added with corn starch to study changes in properties. Different plasticizers might affect the mechanical or thermal properties which bring different behaviours of bioplastic. Moreover, obtaining homogenous smooth films with a similar thickness to the bioplastic, the investigation on photodegradation supported by FT-IR or Gel permeation chromatography, and testing mechanical strength of plastic can be further studied.

\section{Acknowledgements}

The authors would like to thank Curtin University Malaysia for providing the chemicals and equipment for analysis.

\section{References}

[1] Dilkes-Hoffman, L., Pratt, S., Lant, P., \& Laycock, B. (2019). The role of biodegradable plastic in solving plastic solid waste accumulation Plastics to energy (pp. 469-505): Elsevier. https://doi.org/10.1016/B978-012-813140-4.00019-4

[2] El Kadi, S. (2010). Bioplastic production form inexpensive sources bacterial biosynthesis, cultivation system, production and biodegrability. USA: VDM (Verlag Dr. Muller) Publishing House.

[3] Villanueva, A., \& Eder, P. (2014). End-of-waste criteria for waste plastic for conversion. Institute for Prospective Technological Studies. ISSN 1831-9424

[4] Barnes, D. K., Galgani, F., Thompson, R. C., \& Barlaz, M. (2009). Accumulation and fragmentation of plastic debris in global environments. Philosophical transactions of the royal society B: biological sciences, 364(1526), 1985-1998. https://doi.org/10.1098/rstb.2008.0205

[5] Álvarez-Chávez, C. R., Edwards, S., Moure-Eraso, R., \& Geiser, K. (2012). Sustainability of bio-based plastics: general comparative analysis and recommendations for improvement. Journal of cleaner production, 23(1), 47-56. https://doi.org/10.1016/j.jclepro.2011.10.003

[6] Cinelli, P., Chiellini, E., Lawton, J., \& Imam, S. (2006). Foamed articles based on potato starch, corn fibers and poly (vinyl alcohol). Polymer Degradation and Stability, 91(5), 1147-1155. https://doi.org/10.1016/j.polymdegradstab.2005.07.001

[7] Hwang, J., Choi, D., Han, S., Jung, S. Y., Choi, J., \& Hong, J. (2020). Potential toxicity of polystyrene microplastic particles. Scientific reports, 10(1), 1-12. https://doi.org/10.1038/s41598-020-64464-9

[8] Ishrat, M., Mamta, T., \& Vikas, N. (2018). Biodegradable packaging materials. Encyclopedia of renewable and sustainable materials, 2, 688-697. doi: https://doi.org/10.1016/B978-0-12-803581-8.10356-X

[9] Rahman, M. H., \& Bhoi, P. R. (2021). An overview of non-biodegradable bioplastics. Journal of cleaner production, 126218. https://doi.org/10.1016/j.jclepro.2021.126218

[10] Arikan, E. B., \& Ozsoy, H. D. (2015). A review: investigation of bioplastics. J. Civ. Eng. Arch, 9, $188-192$. doi: 10.17265/1934-7359/2015.02.007

[11] Pathak, S., Sneha, C., \& Mathew, B. B. (2014). Bioplastics: its timeline based scenario \& challenges. Journal of Polymer and Biopolymer Physics Chemistry, 2(4), 84-90. DOI:10.12691/jpbpc-2-4-5

[12] Zulkafli, N. N. (2014). Production of Bioplastic from Agricultural Waste. UMP.

[13] Rani, M., \& Shanker, U. (2021). Plastic Degradation and its Environmental Implications. Degradation of Plastics, 99, 290-324. https://doi.org/10.21741/9781644901335-12

[14] Siracusa, V., Rocculi, P., Romani, S., \& Dalla Rosa, M. (2008). Biodegradable polymers for food packaging: a review. Trends in Food Science \& Technology, 19(12), 634-643. https://doi.org/10.1016/j.tifs.2008.07.003

[15] Reddy, C., Ghai, R., \& Kalia, V. C. (2003). Polyhydroxyalkanoates: an overview. Bioresource technology, 87(2), 137-146. https://doi.org/10.1016/S0960-8524(02)00212-2

[16] Nair, L. S., \& Laurencin, C. T. (2007). Biodegradable polymers as biomaterials. Progress in polymer science, 32(8-9), 762-798. https://doi.org/10.1016/j.progpolymsci.2007.05.017

[17] Cho, R. (2018). The truth about bioplastics. State of the Planet.

[18] Sultan, N. F. K., \& Johari, W. L. W. (2017). The development of banana peel/corn starch bioplastic film: A preliminary study. Bioremediation Science and Technology Research, 5(1), 12-17. e-ISSN 2289-5892

[19] Mohammad, N. N., Rabu, M., Adnan, M., \& Rosali, M. (2019). An overview of the grain corn industry in Malaysia. from Food and fertilizer technology center agricultural policy platform http://ap.fftc.agnet.org/ap db.php?id=965\&print=1

e-ISSN: 2289-7771

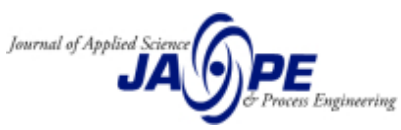


[20] Jeevahan, J., \& Chandrasekaran, M. (2018). Effect of Olive oil Concentrations on film properties of edible composite films prepared from Corn starch and Olive oil. Res. J. Pharm. Technol, 11, 4934. http://dx.doi.org/10.5958/0974-360X.2018.00898.3

[21] Gujar, S., Pandel, B., \& Jethoo, A. (2014). Effect of plasticizer on mechanical and moisture absorption properties of eco-friendly corn starch-based bioplastic. Nature Environment and Pollution Technology, 13(2), 425. ISSN: 0972-6268

[22] Törnqvist, L., Vartia, P., \& Vartia, Y. O. (1985). How should relative changes be measured? The American Statistician, 39(1), 43-46. https://doi.org/10.1080/00031305.1985.10479385

[23] Judawisastra, H., Sitohang, R., \& Marta, L. (2017). Water absorption and its effect on the tensile properties of tapioca starch/polyvinyl alcohol bioplastics. Paper presented at the IOP Conference Series: Materials Science and Engineering.https://doi.org/10.1088/1757-899X/223/1/012066

[24] AS, T. a. D. (n.d.). Past Weather in Miri, Sarawak, Malaysia. Retrieved 23rd May 2021, 2021, from https://www.timeanddate.com/weather/malaysia/miri/historic

[25] Ratnayake, W. S., \& Jackson, D. S. (2006). Gelatinization and solubility of corn starch during heating in excess water: new insights. Journal of Agricultural and Food Chemistry, 54(10), 3712-3716. https://doi.org/10.1021/jf0529114

[26] Zhao, X.-R., Xu, X., Teng, J., Zhou, N., Zhou, Z., Jiang, X.-Y., Yu, J.-G. (2019). Three-dimensional porous graphene oxide-maize amylopectin composites with controllable pore-sizes and good adsorption-desorption properties: Facile fabrication and reutilization, and the adsorption mechanism. Ecotoxicology and environmental safety, 176, 11-19. https://doi.org/10.1016/j.ecoenv.2019.03.069

[27] Amin, M. R., Chowdhury, M. A., \& Kowser, M. A. (2019). Characterization and performance analysis of composite bioplastics synthesized using titanium dioxide nanoparticles with corn starch. Heliyon, 5(8), e02009.

[28] Mendes, J., Paschoalin, R., Carmona, V., Neto, A. R. S., Marques, A., Marconcini, J., Oliveira, J. (2016). Biodegradable polymer blends based on corn starch and thermoplastic chitosan processed by extrusion. Carbohydrate polymers, 137, 452-458. https://doi.org/10.1016/j.carbpol.2015.10.093

[29] Ismail, N. A., Mohd Tahir, S., Yahya, N., Abdul Wahid, M. F., Khairuddin, N. E., Hashim, I., ... \& Abdullah, M. A. (2016). Synthesis and characterization of biodegradable starch-based bioplastics. In Materials Science Forum, 846, 673-678). Trans Tech Publications Ltd. https://doi.org/10.4028/www.scientific.net/MSF.846.673

[30] Garlotta, D. (2001). A literature review of poly (lactic acid). Journal of Polymers and the Environment, 9(2), 63-84. https://doi.org/10.1023/A:1020200822435

[31] El Seoud, O. A., Nawaz, H., \& Arêas, E. P. (2013). Chemistry and applications of polysaccharide solutions in strong electrolytes/dipolar aprotic solvents: an overview. Molecules, 18(1), 1270-1313. https://doi.org/10.3390/molecules 18011270

[32] Puspita, P. S., \& Hermana, W. (2019). Effect of isoamylase application on chemical characteristic of cassava root meal starch. In IOP Conference Series: Earth and Environmental Science, 251(1), 012058. IOP Publishing..https://doi.org/10.1088/1755-1315/251/1/012058

[33] Marichelvam, M., Jawaid, M., \& Asim, M. (2019). Corn and rice starch-based bio-plastics as alternative packaging materials. Fibers, 7(4), 32. https://doi.org/10.3390/fib7040032

[34] Abolibda, T. Z. Y. (2015). Physical and chemical investigations of starch based bio-plastics. University of Leicester.

[35] Tai, N., Adhikari, R., Shanks, R., \& Adhikari, B. (2019). Aerobic biodegradation of starch-polyurethane flexible films under soil burial condition: Changes in physical structure and chemical composition. International Biodeterioration \& Biodegradation, $\quad 145, \quad 104793$. https://doi.org/10.1016/j.ibiod.2019.104793

[36] Wahyuningtiyas, N. E., \& Suryanto, H. (2017). Analysis of biodegradation of bioplastics made of cassava starch. Journal of Mechanical Engineering Science and Technology (JMEST), 1(1), $24-31$. http://dx.doi.org/10.17977/um016v1i12017p024

[37] Wei, L., \& McDonald, A. G. (2016). Accelerated weathering studies on the bioplastic, poly (3hydroxybutyrate-co-3-hydroxyvalerate). Polymer Degradation and Stability, 126, 93-100. https://doi.org/10.1016/j.polymdegradstab.2016.01.023

[38] Ji, Y., Zhang, T., Gui, X., Shi, H., \& Yun, Z. (2020). Solventless ketalization of glycerol to solketal with acetone over the ionic liquid [P (C4H9) 3C14H29][TsO]. Chinese Journal of Chemical Engineering, 28(1), 158-164. https://doi.org/10.1016/j.cjche.2019.07.019

e-ISSN: 2289-7771

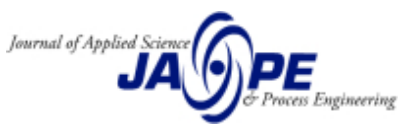

